\title{
Mediation of the malignant biological characteristics of gastric cancer cells by the methylated CpG islands in RNF180 DNA promoter
}

\author{
Jingyu Deng ${ }^{1}$, Jiangtao Guo ${ }^{1}$, Xiaofan Guo ${ }^{1}$, Yachao Hou ${ }^{1}$, Xingming Xie ${ }^{1}$, Changyu \\ Sun ${ }^{1}$, Rupeng Zhang ${ }^{1}$, Xiaohua Yu ${ }^{2}$, Han Liang ${ }^{1}$ \\ ${ }^{1}$ Department of Gastroenterology, Tianjin Medical University Cancer Hospital, City Key Laboratory of Tianjin Cancer Center \\ and National Clinical Research Center for Cancer, Tianjin, China \\ ${ }^{2}$ Department of Technical Quality, Tianjin Zhongxin Pharmaceutical Group Corporation Limited, Traditional Chinese Medicine \\ Factory, Tianjin, China \\ Correspondence to: Jingyu Deng, email: dengery@126.com \\ Han Liang, email: tjlianghan@sohu.com \\ Keywords: ring finger protein 180, methylation, proliferation, invasion, apoptosis \\ Received: December 18, $2015 \quad$ Accepted:May 04, $2016 \quad$ Published: May 20, 2016
}

ABSTRACT

We previously demonstrated that the methylation of ring finger protein $\mathbf{1 8 0}$ (RNF180) DNA promoter was specific to gastric cancer tissues. We reported that four hypermethylated CpG islands, namely, CpG-116, CpG-80, CpG+97, and CpG+102, in RNF180 promoter were significantly associated with the postoperative overall survival of gastric cancer patients. Correlation analysis revealed that the methylated status of CpG islands was significantly associated with the lymph node metastasis of gastric cancer. We formulated four types of MGC-803 cells with the specific demethylation of one of the four CpG islands through vector transfection method. Conventional detections for the biological characteristics of cancer cells showed that 1 ) the methylation of $\mathrm{CpG}+102$ island in RNF180 DNA promoter could remarkably influence the comprehensively malignant biological characteristics of gastric cancer cells, including their proliferation, invasion, cell cycle, anti-apoptosis, and tumorigenicity. 2) The CpG+97 island, in addition to the CpG+102 island, should be considered as the other key methylated locus in RNF180 DNA promoter to mediate the malignant biological characteristics of gastric cancer cells. The methylated status of the key CpG islands of RNF180 DNA promoter may be used to predict the variations of the malignant biological characteristics of gastric cancer cells. The proposed method is a promising molecular therapy for gastric cancer.

\section{INTRODUCTION}

DNA methylation, which is the main epigenetic feature of DNA, mainly functions in gene transcriptional regulation and activates many cellular processes, including oncogenesis [1]. Thus far, various human malignancies are characterized by aberrancies in DNA methylation [2]. $\mathrm{CpG}$ islands are $\mathrm{CpG}$-rich regions located in more than half of the promoters of mammalian genes; these islands exhibit exceptional and global unmethylated patterns [3-5]. The methylation of $\mathrm{CpG}$ islands modifies the transcriptional activity of key proliferation genes or transcription factors involved in cell growth suppression or promotion [6]. Gene-specific hypermethylation at certain tumorsuppressor gene sites and transcriptional inactivation by cytosine methylation at promoter $\mathrm{CpG}$ islands may silence tumor suppressor genes in oncogenesis [7, 8]. In several human cancer types, subgroups defined by distinctive methylation patterns have been linked to several features, such as tumor size in breast cancer [9], tumor type in lung [10], and tumor histology in glioma [11]. First proposed in 1999 by Toyota [12], the $\mathrm{CpG}$ island methylator phenotype (CIMP) in colorectal cancer is a well-studied methylation-defined subgroup. CIMP is defined as a widespread and increased level of DNA methylation in various human malignancies; it also represents a subclass of tumors with distinctive clinicopathological and molecular features[13]. However, a screen of methylated genes that can represent distinctive characteristics from various gastric tumors is difficult to accomplish because 
of the heterogeneity of gastric cancer tissues. The function of specially methylated $\mathrm{CpG}$ islands in DNA promoters in gastric cancer has been extensively investigated. In a previous study, the methylation of ring finger protein 180 (RNF180) DNA promoter is specific to gastric cancer tissues, and four hypermethylated $\mathrm{CpG}$ islands, namely, $\mathrm{CpG}-116$, $\mathrm{CpG}-80, \mathrm{CpG}+97$, and $\mathrm{CpG}+102$, in RNF180 promoter are significantly associated with the postoperative overall survival of gastric cancer patients [14]. Correlation analyses revealed that the methylated status of $\mathrm{CpG}$ islands is significantly associated with the lymph node metastasis of gastric cancer [14]. Therefore, various methylated $\mathrm{CpG}$ islands may elicit different effects on the mediation of the biological behaviors of gastric cancer cells during canceration. This present study aimed to investigate whether CpG-116, CpG-80, $\mathrm{CpG}+97$, and $\mathrm{CpG}+102$ in RNF180 DNA promoter can moderate the malignant biological characteristics of gastric cancer cells to alter the progression of this disease.

\section{RESULTS}

\section{Detection of the $\mathrm{CpG}$ island demethylation of RNF180 DNA promoters in various MGC-803 cell lines}

Figure 1 shows that the four types of RNF180 DNA promoter fragments, including the various cytosine-
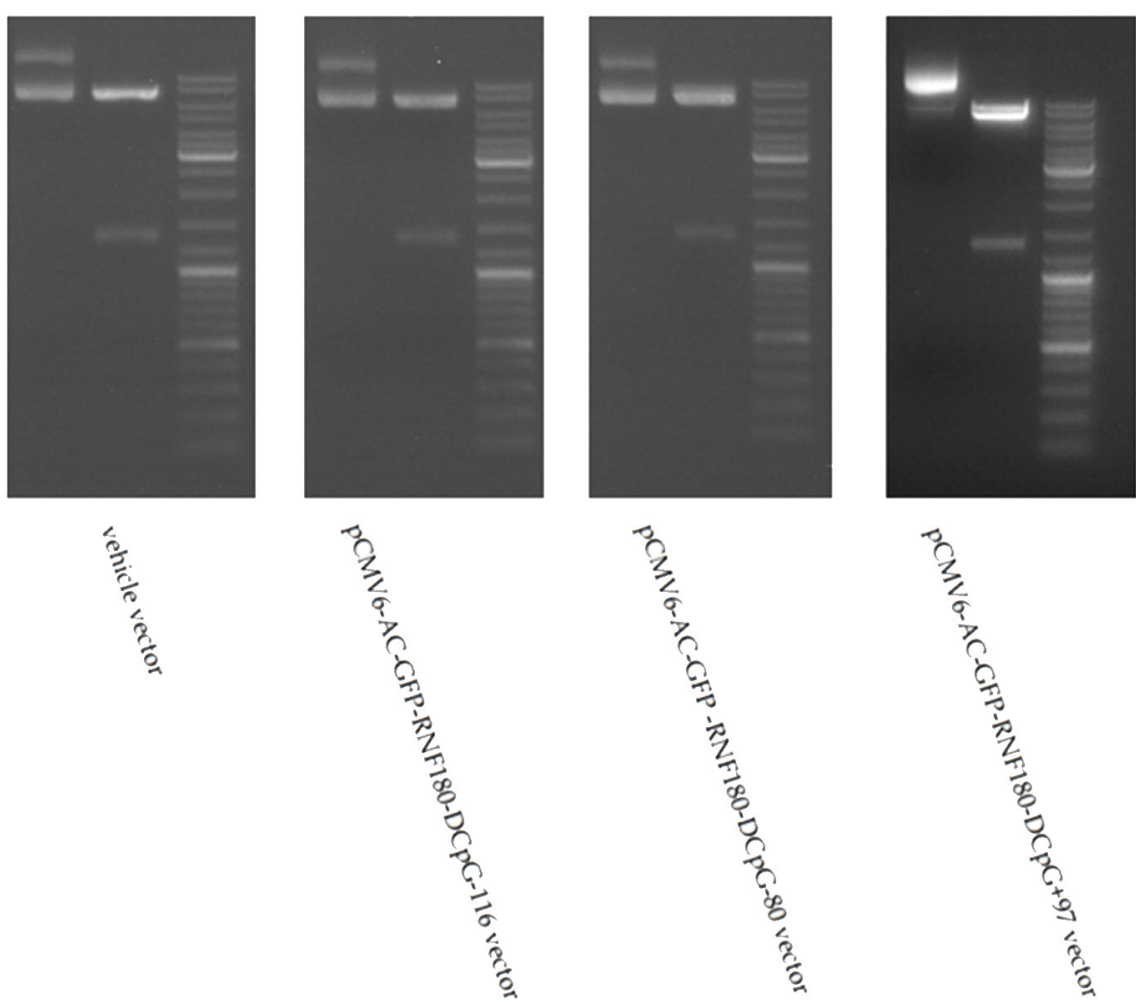

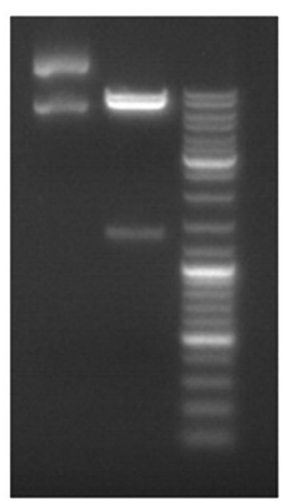

thymine conversion in corresponding $\mathrm{CpG}$ islands $(\mathrm{CpG}-$ 116, CpG-80, $\mathrm{CpG}+97$, or $\mathrm{CpG}+102$ ), were successfully subcloned in the pCMV6-AC-GFP-RNF180 vectors. With BGS detection, we demonstrated that the four cancer cell lines transfected with the various demethylated $\mathrm{CpG}$ island vectors were manufactured (Figure 2). Subsequently, we also detected the transcriptional levels (mRNA) of RNF180 gene in four kinds of MGC803 cell lines, which were transfected with the various demethylated $\mathrm{CpG}$ island vectors; and MGC-803 cell line, which was transfected with the vehicle vector. As expected, all four kinds of MGC-803 cell lines transfected with various demethylated $\mathrm{CpG}$ island vectors (pCMV6RNF180-DCpG-116, pCMV6-RNF180-DCpG-80, pCMV6-RNF180-DCpG+97, and pCMV6-RNF180$\mathrm{DCpG}+102$ ) showed considerably increased RNF180 mRNA mean relative expression values (MREV) $\left(\mathrm{MREV}_{\mathrm{CpG}-116}=0.862, \mathrm{MREV}_{\mathrm{CpG}-80}=0.946, \mathrm{MREV}_{\mathrm{CpG}+97}\right.$ $=1.011$, and $\left.\mathrm{MREV}_{\mathrm{CpG}+102}=1.007\right)$. In comparison, MGC-803 cell line transfected with vehicle vector revealed the approximate silence of RNF180 mRNA $(\mathrm{MREV} v e h i c l e=0.099)\left(\mathrm{P}_{\mathrm{CpG}-116 \text { vs vehicle }}<0.001, \mathrm{P}_{\mathrm{CpG}-80 \mathrm{vs}}\right.$ vehicle $=0.001, \mathrm{P}_{\mathrm{CpG}+97 \text { vS vehicle }}<0.001$, and $\mathrm{P}_{\mathrm{CpG}+102 \text { vs vehicle }}$ $<0.001$ ) (Figure 3). Therefore, we were convinced that the four kinds of MGC-803 cell lines transfected with various demethylated $\mathrm{CpG}$ island vectors may serve as potential key sites of re-expressing RNF180 for the regulation the biological functions of MGC-803 cells.
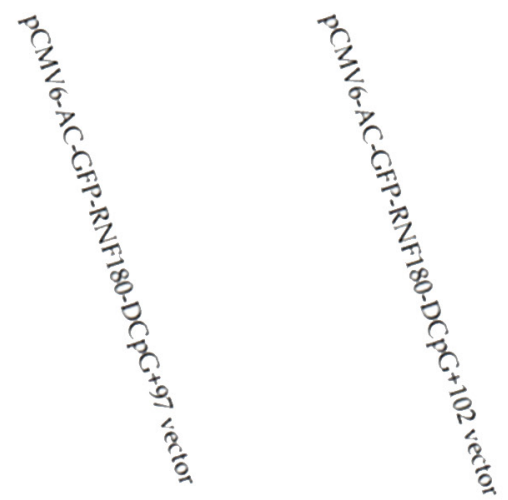

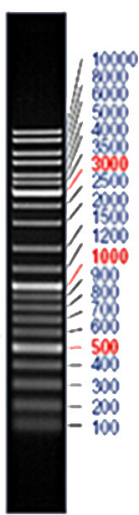

$\mathrm{M}$

Figure 1: Macrorestriction maps for MGC-803 cells transfected with various vectors. 


\section{CpG island demethylation of RNF180 DNA promoter activates gene transcriptions of malignant biological characteristics of MGC-803 cells}

The potential molecular mechanism of $\mathrm{CpG}$ island demethylation in the RNF180 DNA promoter regulation was also explored. The malignant biological characteristics of gastric cancer cells, or the MREV of the common genes involved in the tumor progression, were used to assess the expression differences among the four MGC-803 cell lines transfected with various demethylated $\mathrm{CpG}$ island vectors (pCMV6-RNF180DCpG-116, pCMV6-RNF180-DCpG-80, pCMV6RNF180-DCpG+97, and pCMV6-RNF180-DCpG+102) and MGC-803-vehicle cell line. With the RT-PCR assay, we demonstrated that all four kinds of MGC803 cell lines transfected respectively with various demethylated $\mathrm{CpG}$ island vectors presented lower MREVs of Ki-67, MMP-2, VEGF-A, VEGF-C, and VEGF-D than those of the MGC-803-vehicle cell line. Notably, MGC-803-pCMV6-RNF180-DCpG+102 cancer cell lines presented the lowest MREV of Ki$67\left(\mathrm{P}_{\mathrm{CpG}+102 \text { vs vehicle }}=0.031\right), \mathrm{MMP}-2\left(\mathrm{P}_{\mathrm{CpG}+102 \text { vs vehicle }}\right.$

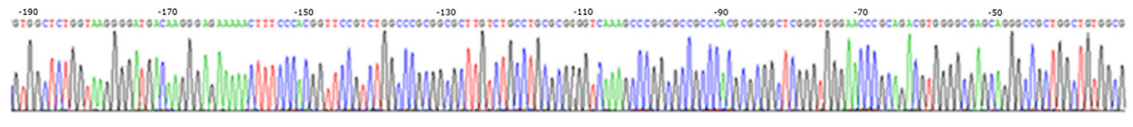

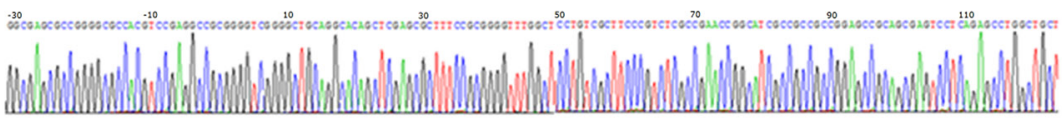
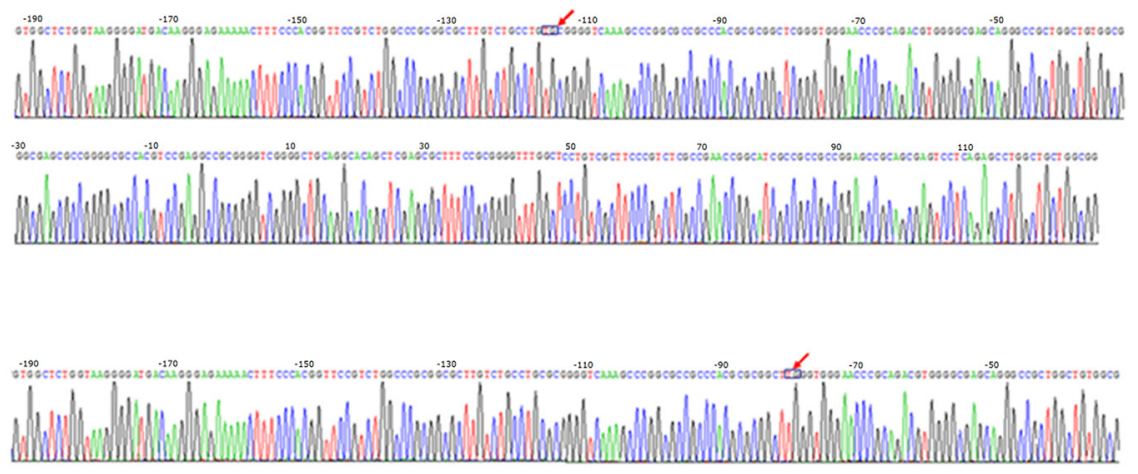

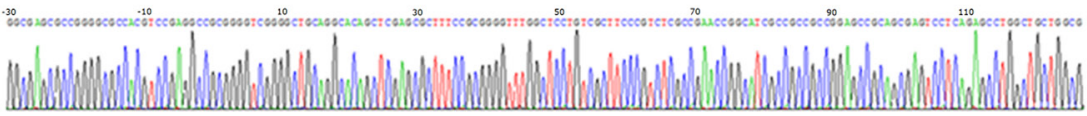
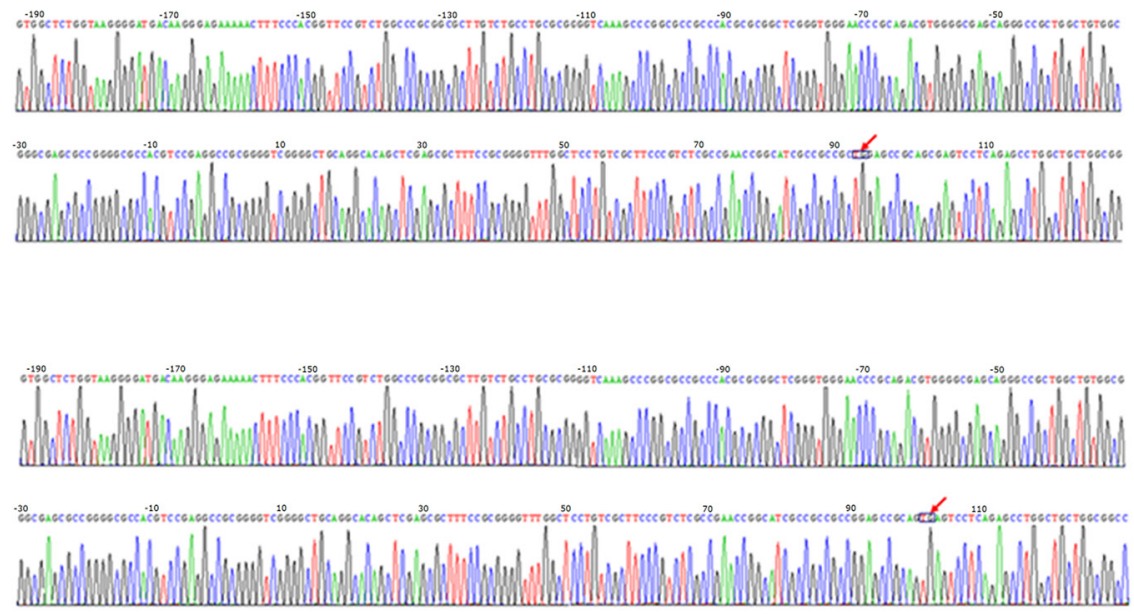

vehicle vector

pCMV6-AC-GFP-RNF180-DCpG-116 vector

pCMV6-AC-GFP-RNF180-DCpG-80 vector

pCMV6-AC-GFP-RNF180-DCpG+97 vector

pCMV6-AC-GFP-RNF180-DCpG+102 vector

Figure 2: Bisulphite sequencing figures for MGC-803 cells transfected with various vectors. 
$=0.034)$, VEGF-A $\left(\mathrm{P}_{\mathrm{Cp}}\right.$ $\left(\mathrm{P}_{\mathrm{CpG}+102 \text { vs vehicle }}=0.118\right)$, and CCR-7 $\left(\mathrm{P}_{\mathrm{CpG}+102 \text { vs vehicle }}\right.$ $=0.001)$ among the above-mentioned cancer cell lines. Additionally, MGC-803-pCMV6-RNF180-DCpG+102 cancer cell lines presented the second lowest MREV of VEGF-C $\left(\mathrm{P}_{\mathrm{CpG}+102 \text { vs vehicle }}=0.045\right)$ among the abovementioned cancer cell lines, following by MGC-803-

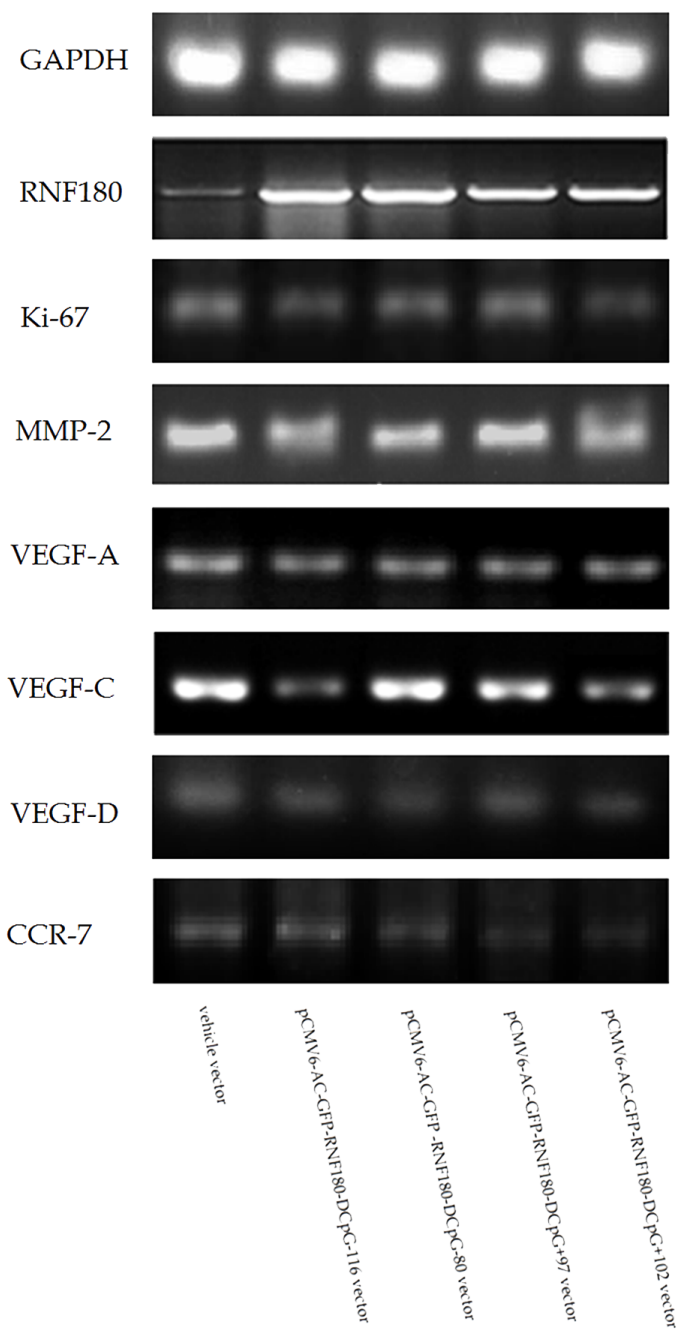

pCMV6-RNF180-DCpG-116 cancer cell line $\left(\mathrm{P}_{\mathrm{CpG}+97}\right.$ $=0.036)$. These gene transcription detection results suggested that the methylation of $\mathrm{CpG}+102$ island of RNF180 promoter may enhance the malignant biological characteristics of MGC-803 cells and contribute to the progression of gastric cancer, including lymphatic invasion.

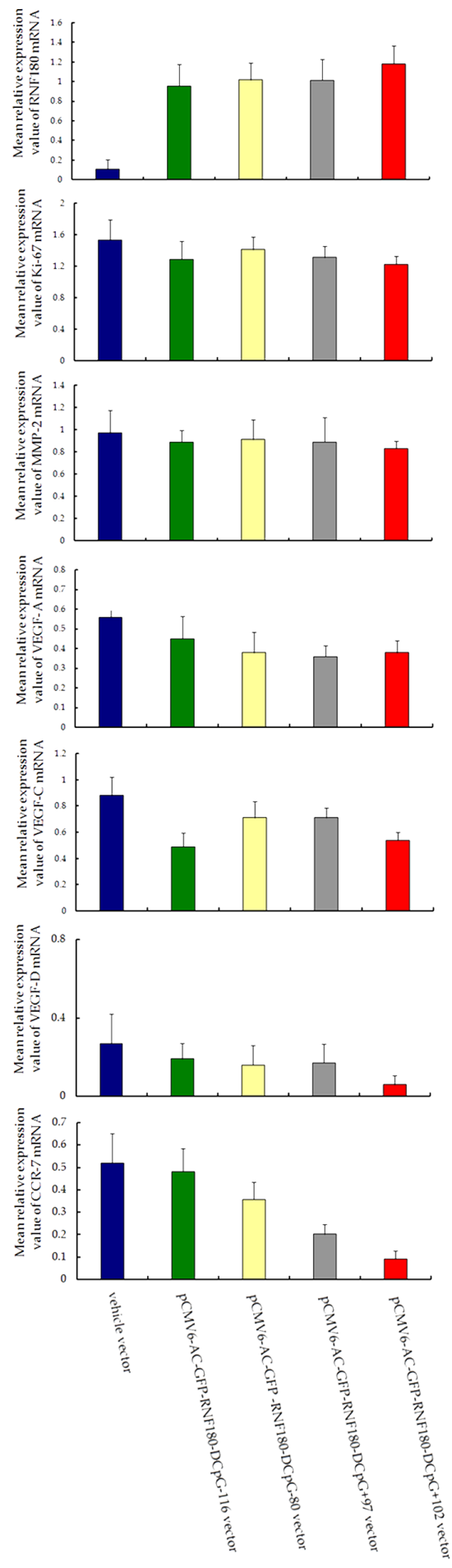

Figure 3: RT-PCR detection RNF180mRNA expression for MGC-803 cells transfected with various vectors. 


\section{CpG island demethylation of RNF180 DNA promoter inhibits MGC-803 cell proliferation and viability}

We detected the effect of various $\mathrm{CpG}$ island demethylation of RNF180 DNA promoter on MGC-803 cell growth and viability using colony formation and MTT assay. The colonies formed by MGC-803-vehicle cell line were significantly more than those of the MGC803 cell lines transfected with various demethylated CpG island vectors (vehicle 368 \pm 47 , pCMV6-RNF180DCpG-116 182 \pm 31 , pCMV6-RNF180-DCpG-80 192 \pm 34 ,

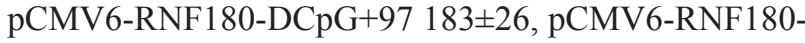
$\mathrm{DCpG}+102158 \pm 18 ; \mathrm{P}_{\mathrm{CpG}-116 \text { vs vehicle }}=0.017, \mathrm{P}_{\mathrm{CpG}-80 \text { vs vehicle }}$ $=0.026, \mathrm{P}_{\mathrm{CpG}+97 \mathrm{VS} \text { vehicle }}=0.021$, and $\left.\mathrm{P}_{\mathrm{CpG}+102 \text { VS vehicle }}=0.005\right)$
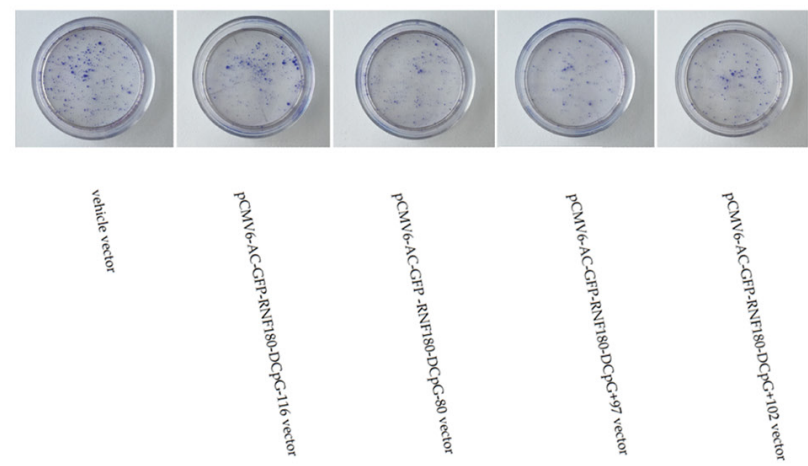

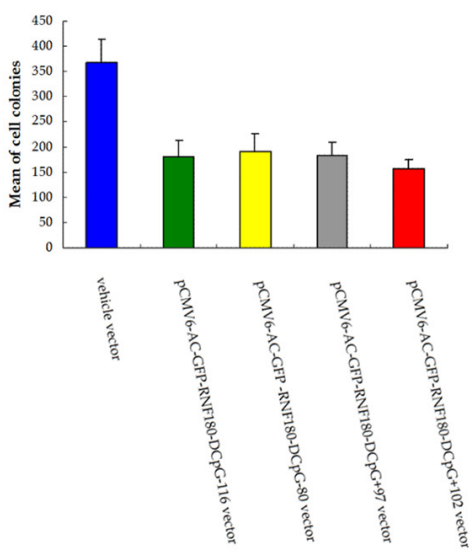

A

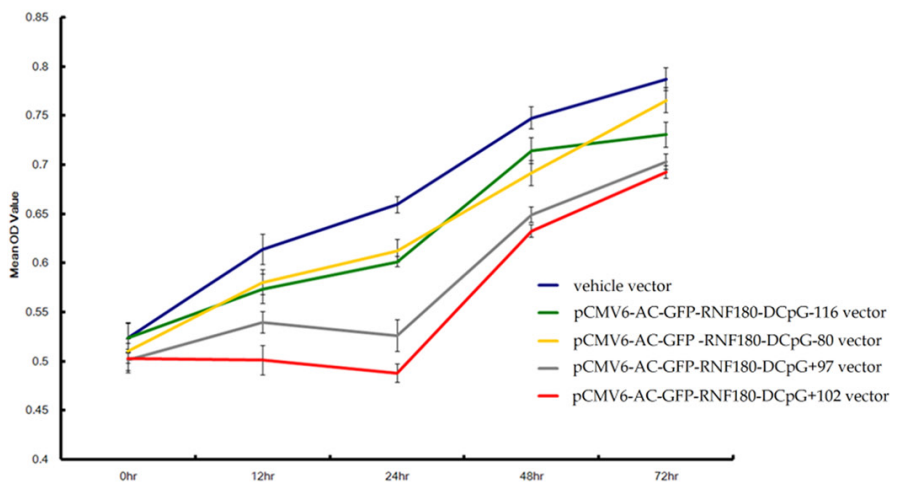

B

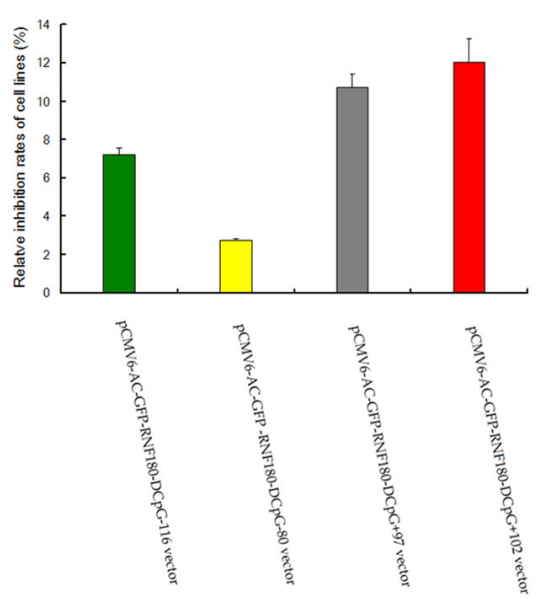

Figure 4: Colony formation A. and MTT assay B. for MGC-803 cells transfected with various vectors. 


\section{CpG island demethylation of RNF180 DNA promoter inhibits MGC-803 cell migration}

Scratch assays were performed to observe the function of various $\mathrm{CpG}$ island demethylation of RNF180 DNA promoter in MGC-803 cell migration. As shown in Figure 5, cell migration was significantly inhibited in the two MGC803 cell lines transfected with demethylated $\mathrm{CpG}$ island vectors (pCMV6-RNF180-DCpG-116 and pCMV6-RNF180$\mathrm{DCpG}+97$ ) compared with that in the MGC-803 cell line transfected with vehicle vector. The scratch health rates of all five cell lines were $30.41 \%, 26.25 \%, 38.17 \%, 21.25 \%$, and $33.26 \%$ for MGC-803-vehicle, MGC-803-pCMV6-RNF180DCpG-116 cells, MGC-803-pCMV6-RNF180-DCpG-80 cells, MGC-803-pCMV6-RNF180-DCpG+97 cells, and
MGC-803-pCMV6-RNF180-DCpG+102 cells at $48 \mathrm{~h}$ timepoint, respectively. This finding indicated that methylation of CpG-116 and CpG+97 islands of RNF180 DNA promoter could significantly enhance the migration of gastric cancer cells $\left(\mathrm{P}_{\mathrm{CpG}-116 \text { VS vehicle }}=0.031\right.$ and $\left.\mathrm{P}_{\mathrm{CpG}+97 \text { vS vehicle }}=0.024\right)$.

\section{CpG island demethylation of RNF180 DNA promoter inhibits MGC-803 cell invasion}

The various methylated $\mathrm{CpG}$ islands of RNF180 promoter on the invasiveness of MGC-803 cells were studied using Matrigel model. We found that the number of invaded cells was significantly lower in the four kinds of MGC-803 cell lines transfected with the demethylated $\mathrm{CpG}$ island vectors (pCMV6-RNF180-DCpG-116, pCMV6-RNF180-
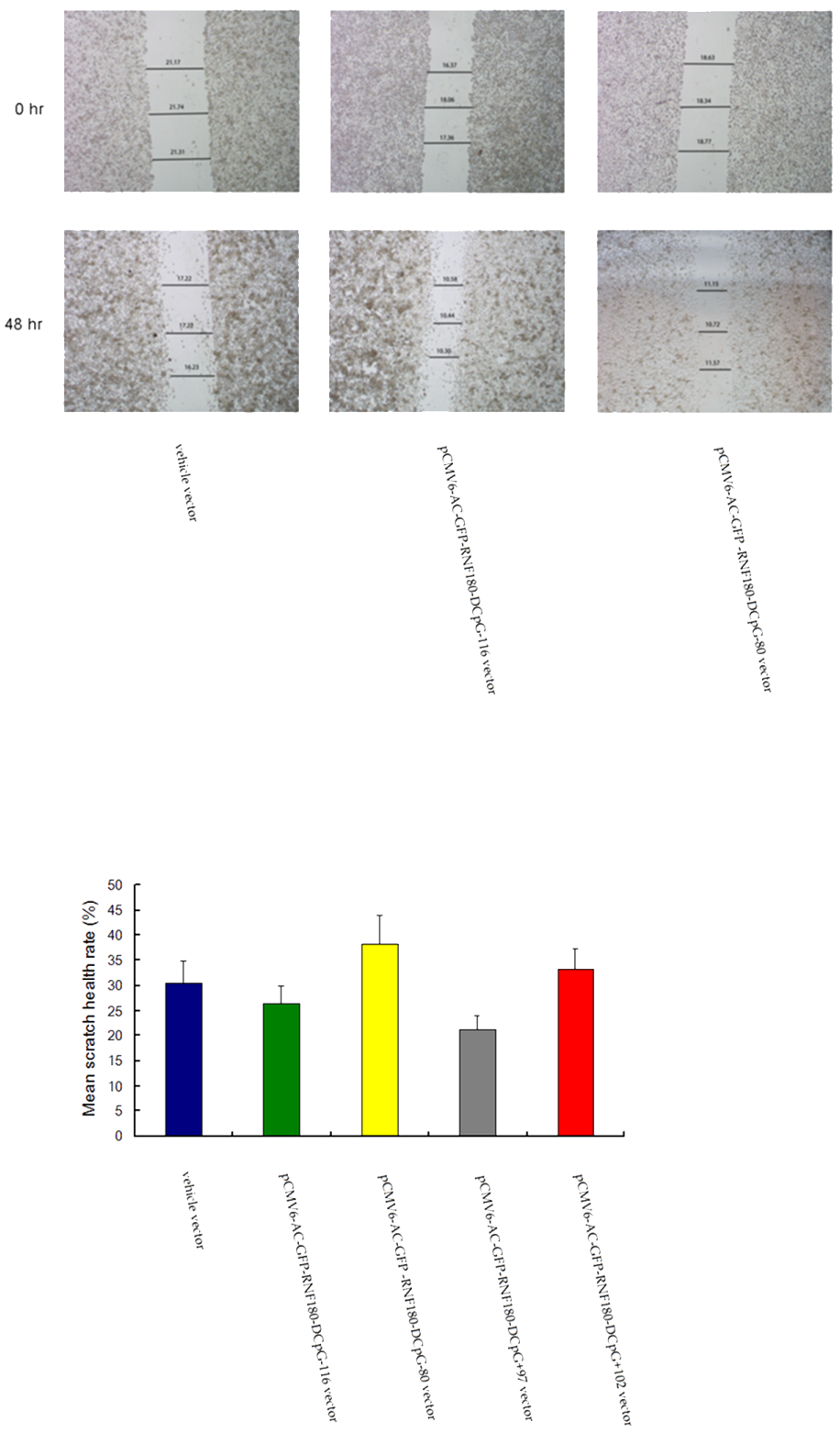
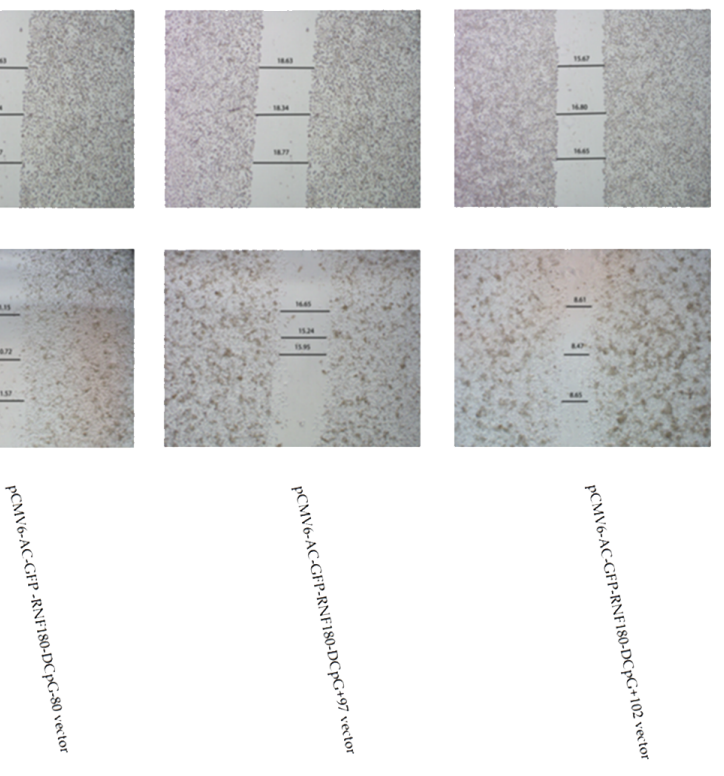

Figure 5: Cell-based scratch assay for MGC-803 cells transfected with various vectors. 
DCpG-80, pCMV6-RNF180-DCpG+97, and pCMV6RNF180-DCpG+102) compared with those in the MGC803 cell line transfected with vehicle vector (Figure 6). The mean cell number of all five cell lines were 24, 18, 16, 16, and 9 for MGC-803-vehicle, MGC-803-pCMV6-RNF180DCpG-116 cells, MGC-803-pCMV6-RNF180-DCpG-80 cells, MGC-803-pCMV6-RNF180-DCpG+97 cells, and MGC-803-pCMV6-RNF180-DCpG+102 cells at $24 \mathrm{~h}$ timepoint respectively. This result indicated that the methylation of four $\mathrm{CpG}$ islands (CpG-116, CpG-80, $\mathrm{CpG}+97$, and $\mathrm{CpG}+102)$ of the RNF180 DNA promoter could enhance the invasion of gastric cancer cells $\left(\mathrm{P}_{\mathrm{CpG}-116 \mathrm{VS} \text { vehicle }}=0.041\right.$, $\mathrm{P}_{\mathrm{CpG}-80 \text { vs vehicle }}=0.020, \mathrm{P}_{\mathrm{CpG}+97 \text { vs vehicle }}=0.023$, and $\mathrm{P}_{\mathrm{CpG}+102 \mathrm{vs}}$ $<0.001)$. Of the four above-mentioned $\mathrm{CpG}$ islands, the methylation of the $\mathrm{CpG}+102$ island of RNF180 DNA promoter remarkably enhanced the invasion of MGC-803 cells.

\section{CpG island demethylation of RNF180 DNA promoter improves MGC-803 cell apoptosis}

Compared with the cell apoptosis in the MGC-803 cell line transfected with vehicle vector, cell apoptosis rates were significantly enhanced in the four MGC-803 cell lines transfected with the demethylated $\mathrm{CpG}$ island vectors (pCMV6-RNF180-DCpG-116, pCMV6-RNF180-DCpG-80, pCMV6-RNF180-DCpG+97, and pCMV6-RNF180$\mathrm{DCpG}+102$ ) (Figure 7). The mean cell apoptosis rates of all five cell lines were $0.6 \%, 12.4 \%, 1.5 \%, 3.0 \%$, and $8.2 \%$ for MGC-803-vehicle, MGC-803-pCMV6-RNF180-DCpG-116 cells, MGC-803-pCMV6-RNF180-DCpG-80 cells, MGC803-pCMV6-RNF180-DCpG+97 cells, and MGC-803pCMV6-RNF180-DCpG+102 cells respectively. This finding indicated that the methylation of four CpG islands (CpG-116, CpG-80, CpG+97 and CpG+102) of RNF180 DNA promoter
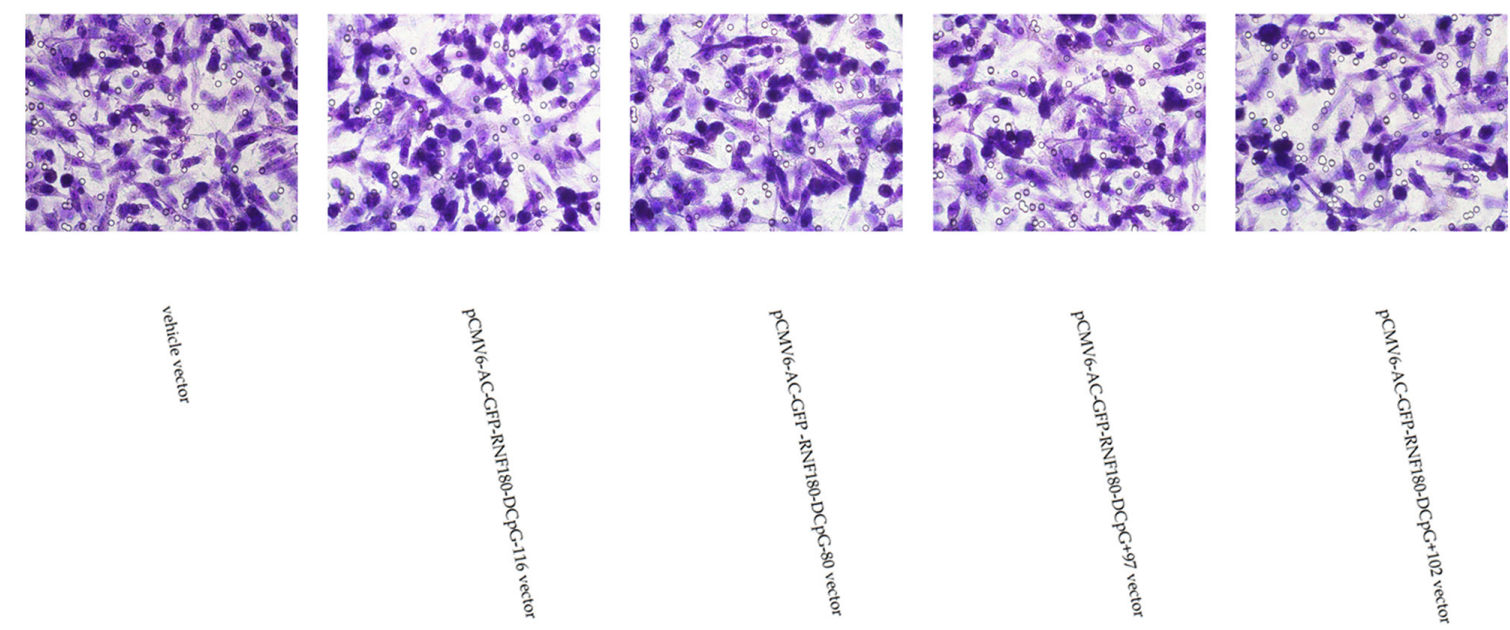

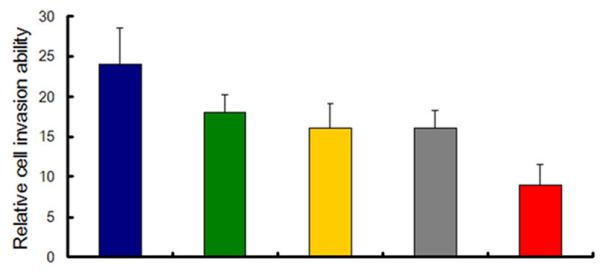

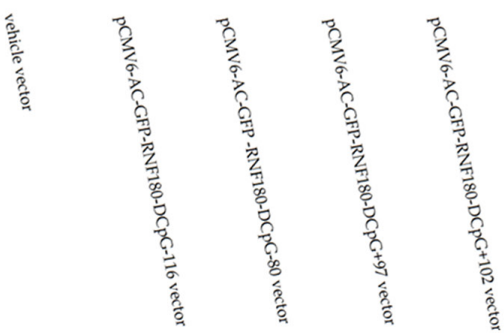

Figure 6: Transwell tumor cell invasive assay for MGC-803 cells transfected with various vectors. 
could enhance the anti-apoptosis of MGC-803 cells $\left(\mathrm{P}_{\mathrm{CpG}-116}\right.$ vs vehicle $<0.001, \mathrm{P}_{\mathrm{CpG}-80 \text { vs vehicle }}=0.036, \mathrm{P}_{\mathrm{CpG}+97 \text { vs vehicle }}=0.011$, and $\mathrm{P}_{\mathrm{CpG}+102 \text { vs vehicle }}<0.001$ ). Of the four abovementioned $\mathrm{CpG}$ islands, the methylation of CpG-116 island of RNF180 DNA promoter could remarkably enhance the invasion of MGC803 cells, followed by the methylation of $\mathrm{CpG}+102$ island.

\section{CpG island demethylation of RNF180 DNA promoter inhibits MGC-803 cell cycle in G2 phase}

Flow cytometry was adopted to detect the cell cycle changes of MGC-803 gastric cells stimulated by the demethylation of various $\mathrm{CpG}$ islands in RNF180 DNA promoter. MGC-803-pCMV6-RNF180-DCpG+97 and MGC-803-pCMV6-RNF180-DCpG+102 cell lines presented higher cell counts in the $\mathrm{S}$ phase and lower cell counts in the $\mathrm{G} 2$ phase compared with those in the MGC-803-vehicle at a $72 \mathrm{~h}$ time-point. The mean diploid ratios of G2 phase cell counts of three cancer cell lines transfected with the demethylated $\mathrm{CpG}$ islands $(\mathrm{CpG}+97$, $\mathrm{CpG}+102$, and vehicle) were $14.94 \%, 13.01 \%$, and $17.27 \%$, respectively (Figure 8). The flow cytometry assay results suggested that the methylation of $\mathrm{CpG}$ islands $(\mathrm{CpG}+97$ and $\mathrm{CpG}+102$ ) of the RNF180 promoter could enhance cell synthesis and improve the mitosis of MGC-803 cancer cells.
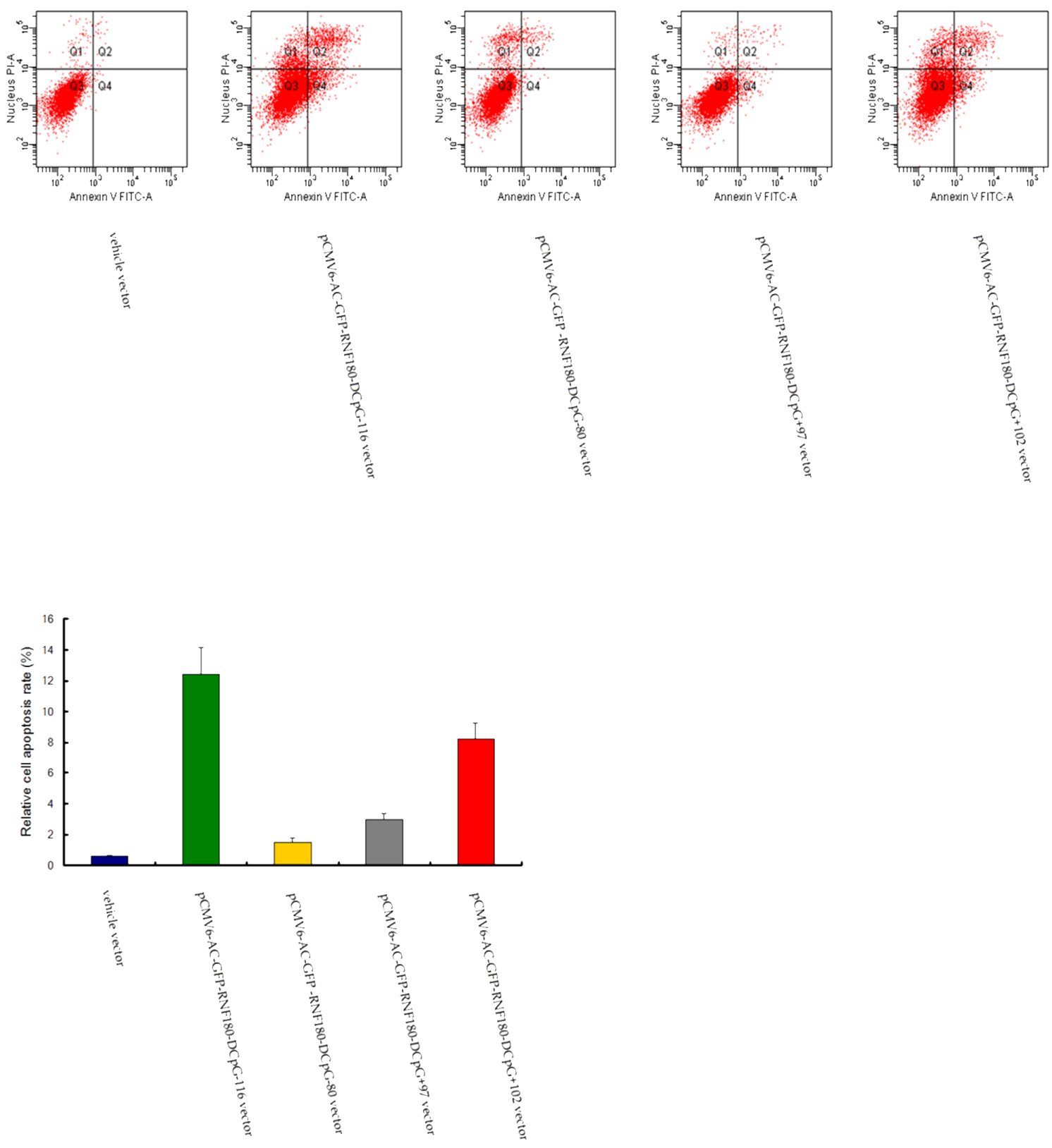

Figure 7: Cell apoptosis detection for MGC-803 cells transfected with various vectors. 


\section{CpG island demethylation of RNF180 DNA promoter inhibits tumor growth in nude mice}

We explored whether the $\mathrm{CpG}$ island demethylation of RNF180 DNA promoter could inhibit the growth of GC cells in nude mice in vivo. The mean tumor sizes in nude mice transfected with the four kinds of MGC-803 cell lines with various $\mathrm{CpG}$ island demethylation in RNF180 DNA promoter were significantly smaller than those transfected with MGC-803-vehicle cells at a four-week time-point after cell implantation $\left(\mathrm{P}_{\mathrm{CpG}-116 \mathrm{VS} \text { vehicle }}=0.031, \mathrm{P}_{\mathrm{CpG}-80 \text { vs vehicle }}\right.$ $=0.014, \mathrm{P}_{\mathrm{CpG}+97 \text { vS vehicle }}=0.001$, and $\left.\mathrm{P}_{\mathrm{CpG}+102 \text { vS vehicle }}<0.001\right)$. This finding indicates that the methylation of four $\mathrm{CpG}$ islands (CpG-116, $\mathrm{CpG}-80, \mathrm{CpG}+97$, and $\mathrm{CpG}+102)$ of RNF180 DNA promoter could improve the tumorigenicity of MGC-803 cells (Figure 9). Of the four $\mathrm{CpG}$ islands previously mentioned, the methylation of $\mathrm{CpG}+102$ island of RNF180 DNA promoter could considerably enhance the tumorigenicity of MGC-803 cells, followed by the methylation of $\mathrm{CpG}+97$ island.

\section{DISCUSSION}

The ubiquitin-proteasome system (UPS) maintains the dynamic equilibrium of the abundance and activity of various cellular proteins; UPS is significantly associated with oncogenesis and tumor progression [15, 16]. RNF180 is an E3 ubiquitin ligase; it is implicated in the ubiquitin-proteasome pathway supported by its binding to the UbcH6 ubiquitin-conjugating enzyme and by its trans-ubiquitination-enhancing activities [17]. RNF180 participates in tumorigenesis and likely suppresses the progression of human cancers $[18,19]$. The loss or downregulation of RNF180 is associated with a significantly increased risk of cancer-related deaths of gastric cancer patients [19]. Furthermore, the promoter methylation of RNF180 DNA, which directly mediates RNF180 transcription silencing, may alter the malignant biological characteristics of gastric cancer cells to accelerate gastric cancer progression [19]. The methylation of various $\mathrm{CpG}$ islands in the RNF180 DNA promoter may elicit different effects on lymph node metastasis associated with gastric cancer $[14,20]$. CpG-116, CpG-80, CpG+97, and $\mathrm{CpG}+102$ in RNF180 promoter are negatively related to the overall survival of gastric cancer patients, as revealed by multivariate analysis [14]. This finding provided a basis for investigations on the methylated status of different CpG islands in RNF180 DNA promoters to elucidate the detailed mechanism of RNF180 suppression in gastric cancer progression.

In this study, four kinds of RNF180 DNA promoter fragments with demethylated CpG-116, CpG80, $\mathrm{CpG}+97$, and $\mathrm{CpG}+102$ were designed by using cytosine-thymine conversions in the locus of RNF180 promoter. Subsequently, four MGC-803 cancer cell lines were transfected with the four RNF180 DNA promoter fragments with demethylated $\mathrm{CpG}$ islands. The transcriptional levels of RNF180 (mRNA) in the four cancer cell lines considerably increased compared with those in the MGC-803-vehicle cell line. Therefore, the demethylation of $\mathrm{CpG}-116, \mathrm{CpG}-80, \mathrm{CpG}+97$, and $\mathrm{CpG}+102$ could increase the transcriptional level of RNF180 in gastric cancer cells. This finding could demonstrate that the methylation of the four $\mathrm{CpG}$ islands of the DNA promoter might reveal the potential inhibition, transcription, expression, and biological function of RNF180 gene. These conclusions provided a solid basis for further studies on the biological effects of the methylation of different $\mathrm{CpG}$ islands in RNF180 DNA promoter on gastric cancer cell. These conclusions could help elucidate the molecular mechanisms by which RNF180 mediates gastric cancer progression.

We applied RT-PCR to detect the mRNA levels of the common genes related to the malignant biological characteristics of gastric cancer cells and to explore the differences in biological characteristics among five MGC-803 cell lines. RT-PCR assay results revealed that the demethylation of $\mathrm{CpG}-116, \mathrm{CpG}-80, \mathrm{CpG}+97$, and $\mathrm{CpG}+102$ in RNF180 DNA promoter could partially suppress the transcriptional levels of common genes
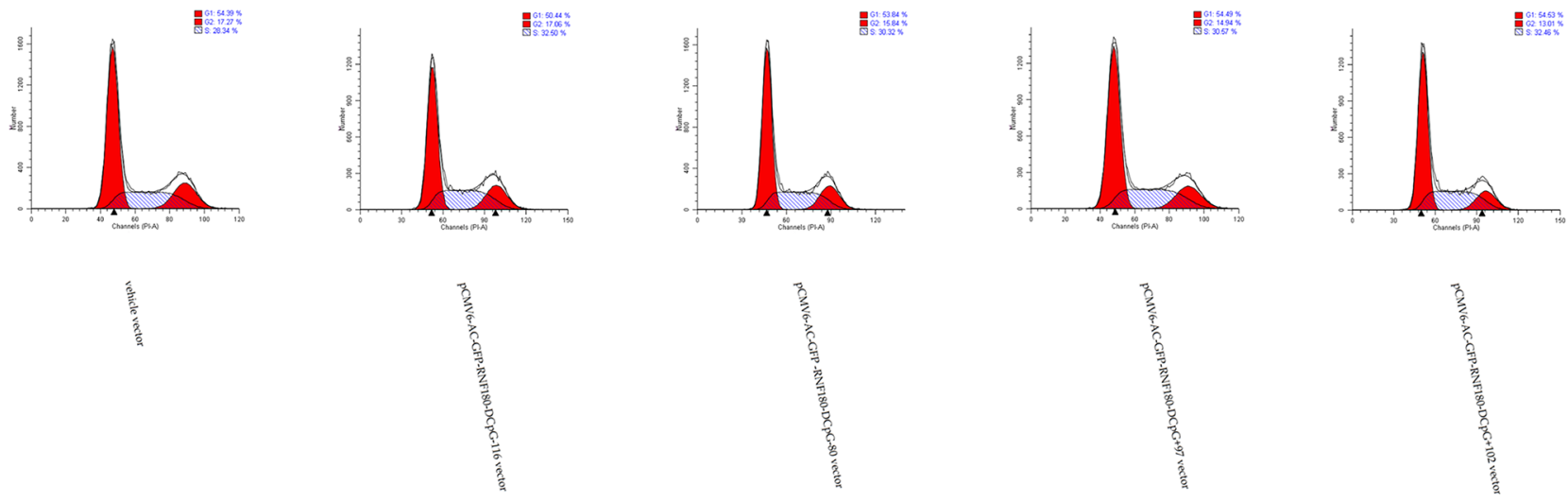

Figure 8: Cell cycle assay for MGC-803 cells transfected with various vectors. 

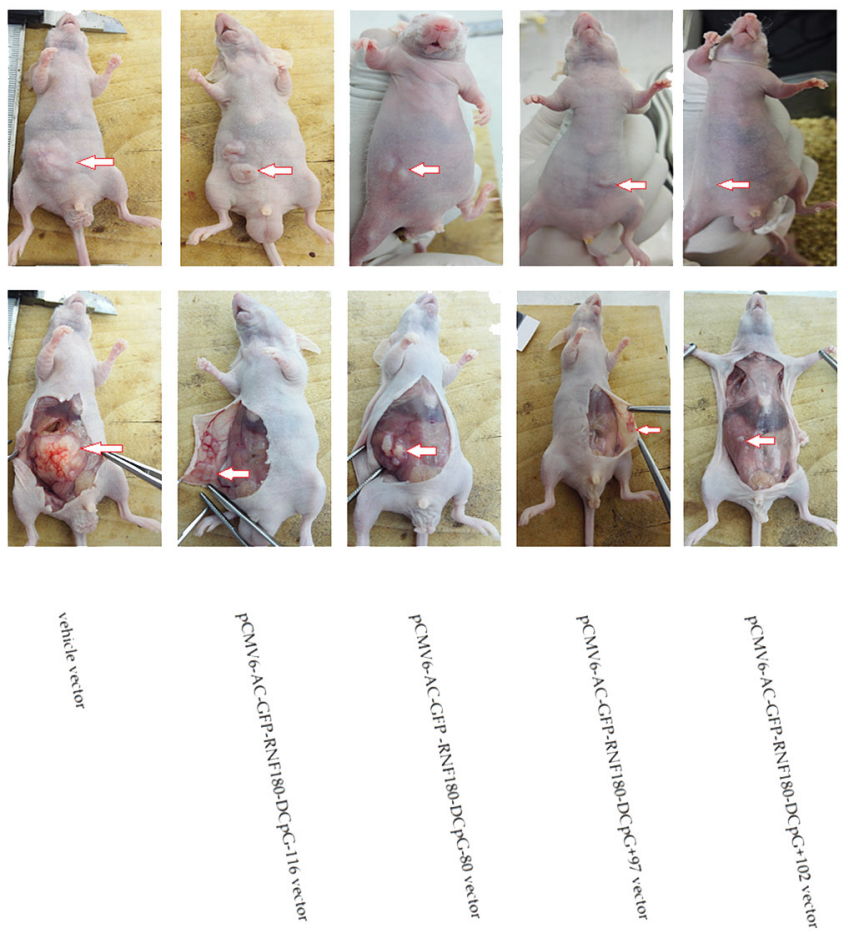
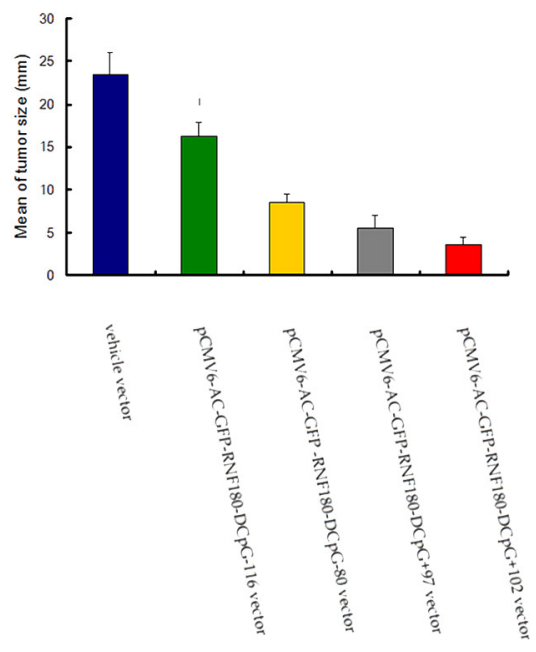

Figure 9: Tumor size measuring for MGC-803 cells transfected with various vectors.

related to the malignant biological characteristics of gastric cancer cells, including proliferation, invasion, angiogenesis, lymphangiogenesis, and chemotaxis.

The demethylation of $\mathrm{CpG}+102$ island in RNF180 DNA promoter could significantly increase the transcriptional value of RNF180 (mRNA) in the MGC803 cell line. Furthermore, the demethylation of $\mathrm{CpG}+102$ island in the RNF180 DNA promoter evidently suppressed the transcriptions of the genes related to the malignant biological characteristics of MGC-803 cells. This result indicated that the methylated status of the $\mathrm{CpG}+102$ island in the RNF180 DNA promoter might be the intensive site associated with gastric cancer progression among four CpG islands in RNF180 DNA promoter. The methylation of the $\mathrm{CpG}+102$ island in RNF180 DNA promoter could promote tumor progression by regulating the malignant biological abilities of MGC-803 cells, including proliferation, invasion, cell cycle, and anti-apoptosis, and by promoting the tumorigenicity of MGC- 803 cells in vivo. Therefore, the methylated status of the $\mathrm{CpG}+102$ island in RNF180 DNA promoter could be a promising molecular therapy to inhibit the malignant characteristics of gastric cancer cells.

Similar to the demethylation of the $\mathrm{CpG}+102$ island, the demethylation of the $\mathrm{CpG}+97$ island in the RNF180 DNA promoter could significantly increase the transcriptional level of RNF180 (mRNA) in the MGC-803 cell line. MTT assay and tumor growth in vivo experiment demonstrated that $\mathrm{CpG}+97$ island was another intensive locus that evidently promoted the tumorigenicity of
MGC-803 cells. Furthermore, the methylation of $\mathrm{CpG}+97$ island in RNF180 DNA promoter significantly contributed to the anti-apoptosis of cancer cells by changing the cell cycle and enhancing the migration capability of gastric cancer cells. The significant increase in the CCR-7 transcriptional level in the MGC-803-pCMV6-RNF180DCpG+97 cell line (following the MGC-803-pCMV6RNF180-DCpG+102 cell line) indicated that the $\mathrm{CpG}+97$ island in RNF180 DNA promoter was the other potential trigger point that promoted the chemotactic movement in the migration and invasion of gastric cancer cells. Lastly, the methylation of $\mathrm{CpG}+97$ island in the RNF180 DNA promoter was associated with the invasive ability of MGC-803 cells through Trans-well chambers. This finding indicated that the methylated status of $\mathrm{CpG}+97$ island in RNF180 DNA promoter was an important contributor to tumor spread. In addition to the methylated status of $\mathrm{CpG}+102$ island, the methylated status of $\mathrm{CpG}+97$ island could be considered as another important locus in the RNF180 DNA promoter to predict the malignancy of gastric cancer cells. The methylated status of $\mathrm{CpG}-$ 116 and CpG-80 islands in the RNF180 DNA promoter mediate several malignant biological behaviors of MGC803 cells. Therefore, these islands were not competent to comprehensively reflect the biological effects of RNF 180 promoter methylation on gastric cancer cells.

We proposed to investigate various $\mathrm{CpG}$ islands in the RNF180 DNA promoter to reveal the key locus of the methylated fragment in the promoter, which could potentially mediate the malignant biological behavior of 
gastric cancer cells, in a manner similar to the definition of CIMP in tumors. On the basis of our previous studies, we demonstrated that the methylation of CpG-116, CpG-80, CpG+97, and CpG+102 in the RNF180 DNA promoter was significantly associated with the prognosis of gastric cancer patients. However, we should elucidate the most intensively methylated $\mathrm{CpG}$ islands that induce the progression of gastric cancer in the RNF180 DNA promoter to develop precise molecular treatments for gastric cancer. The methylated status of the $\mathrm{CpG}+102$ island should be considered the first preferred locus in the RNF180 DNA promoter for the accurate prediction of malignant biological behaviors of gastric cancer cells. This method could be a promising molecular therapy for gastric cancer. The methylated status of the $\mathrm{CpG}+97$ island might also be an alternative to the methylated status of the CpG+102 island in the RNF180 DNA promoter to predict the progression of gastric cancer.

\section{MATERIALS AND METHODS}

\section{Cell lines}

Gastric cancer cell line (MGC-803) was purchased from the Type Culture Collection of the Chinese Academy of Sciences, (Shanghai, China). Cells were cultured in RPMI-1640 medium (Thermo Electron Corporation, Beijing, China) supplemented with $10 \%$ fetal bovine serum (Life Tech, Mulgrave Vic, Australia) and incubated in $5 \% \mathrm{CO} 2$ at $37^{\circ} \mathrm{C}$. The medium was changed twice a week.

\section{Semi-quantitative reverse transcription polymerase chain reaction (RT-PCR) analysis}

Total RNA was extracted from cell lines by Trizol reagent (Invitrogen, Carlsbad, CA). The messenger RNA (mRNA) expression levels of the RNF180, Ki-67, matrix metalloproteinase 2 (MMP-2), vascular endothelial growth factor $\mathrm{A} / \mathrm{C} / \mathrm{D}$ (VEGF-A/C/D), and chemokine receptor 7 (CCR-7) were determined by semi-quantitative Reverse Transcription Polymerase Chain Reaction (RT-PCR) detection. The PCR Cycling conditions for all sequences were 40 cycles of denaturation at $94{ }^{\circ} \mathrm{C}$ for 4 minutes, annealing at $94{ }^{\circ} \mathrm{C}$ for 30 seconds, and extension at $58^{\circ} \mathrm{C}$ for 30 seconds followed by a final extension at $72^{\circ} \mathrm{C}$ for 10 minutes and $4^{\circ} \mathrm{C}$ for 1 minute. All PCR product electrophoreses were performed on a $2 \%$ agarose gel with ethidium bromide and visualized using the Gel Imager system (Asia Xingtai Mechanical and Electrical Equipment Company, Beijing, China). Mean gray value of relative expression of mRNA was defined as the ratio between the mean gray values of the given mRNA expression and the mean gray value of the GAPDH expression. Primers designed and utilized for detected genes were shown in Table 1.

\section{Construction vectors and transfection}

The RNF180 vector was generated by PCR cloning with a mammalian expression vector (pCMV6-AC-GFP) (Origene, USA). The cDNA corresponding to the open reading frame of RNF180 transcript was obtained by RT-PCR amplification of MGC-803 gastric cancer cells' RNA. Four kinds of RNF180 DNA promoter fragments, including the various cytosine - thymine conversion in corresponding CpG islands (CpG-116, CpG-80, CpG+97, or $\mathrm{CpG}+102$ ), were subcloned in the pCMV6-AC-GFPRNF180 vectors to meet requirements of manufacture the different demethylated CpG islands in RNF180 DNA promoter. The identification of all pCMV6-AC-GFP -RNF180-demethylated island vectors and vehicle vector was performed by using the restriction enzyme digestion method (shown in Figure 1). Subsequently, MGC-803 cell line $\left(2 \times 10^{5} /\right.$ well $)$ was transfected with the abovementioned four kinds of RNF180 DNA promoter vectors (including MGC-803-pCMV6-RNF180-DCpG -116, MGC-803-pCMV6-RNF180-DCpG-80, MGC-803pCMV6-RNF180-DCpG+97, or MGC-803-pCMV6RNF180-DCpG+102) and vehicle vector (MGC-803vehicle) using LipofectamineTM 2000 transfection reagent (Invitrogen, NewYork, USA). Transfected cells were selected with Opti-MEM (Invitrogen, NewYork, USA) for 48 hours (hr). Colonies were fixed with methanol/acetone $(1: 1)$, stained with Trypan Blue, and counted [19].

\section{DNA extraction and sodium bisulfite treatment}

Genomic DNA was extracted from gastric cancer cells using QIAamp DNA mini kit (Qiagen, Valencia, CA) following the manufacturer's instructions. Sodium bisulphite modification of genomic DNA was performed by using the EZ DNA Methylation-GoldTM Kit (Zymo Research, Hornby, Canada).

\section{Bisulphite genomic sequencing}

Cells were detected the quantitatively methylated analysis of RNF180 promoter with the bisulphite genomic sequencing method (BGS). Hot start PCR with the bisulfite-treated DNA was performed with a 318bp PCR product spanning promoter region from $-192 \mathrm{bp}$ to $126 \mathrm{bp}$ relative to the transcription start site of RNF180. Forty-three $\mathrm{CpG}$ islands were identified to be contained in the promoter region of RNF180. The sequences of PCR primers were as follows: F:5'-GTGGTTTTGGTAAGGGGATGAT-3'; R:5'CCAACAACCAAACTCTAAAAA CTC-3'. The purified PCR products were cloned into the pUC18-T vector (Biodee, Beijing, China), and six clones for each sample were randomly selected and sequenced by Shanghai Sangon Co.(Shanghai, China). 
Table 1: Primers utilized for target genes detection in all MGC-803 cancer cell lines

\begin{tabular}{|c|c|c|}
\hline Genes & Primer sequences & Length \\
\hline RNF180 & 5'-TCTGACTTTCCTGATGGACCTG/CCTGAGTATTTACССТGCTTCTGT-3' & $(175 b p)$ \\
\hline Ki-67 & 5'-GACGGCCACAAACTCCTAAA/TGCTCTTTCCATCTCCTGCT-3' & $(264 b p)$ \\
\hline MMP-2 & 5'-AGCTCCCGGAAAAGATTGAT/TTTTGCTCCAGTTAAAGGCG-3' & $(215 b p)$ \\
\hline VEGF-A & 5'-CCTTGCCTTGCTGCTCTA/ATGTCCACCAGGGTCTCG-3' & $(150 \mathrm{bp})$ \\
\hline VEGF-C & 5'-GCCCCAAACCAGTAACAATCA/CAGCATCCGAGGAAAACATAAA-3' & $(222 b p)$ \\
\hline VEGF-D & 5'-CTGCCTGATGTCAACTGCTTAG/AGATGATCGCTTCACTGGTCC-3' & $(295 b p)$ \\
\hline CCR-7 & 5'-TGTGGTCGTGGTCTTCATAG/GCGTACAAGAAAGGGTTGAC-3' & $(180 \mathrm{bp})$ \\
\hline GAPDH & 5'-TGGGTGTGAACCATGAGAAGT/TGAGTCCTTCCACGATACCAA-3' & $(124 b p)$ \\
\hline
\end{tabular}

\section{Colony formation assay}

Cells were selected with G418 sulfate (Merck, Darmstadt, Germany) at $0.4 \mathrm{mg} / \mathrm{mL}$ for 2 weeks. Colonies were fixed with methanol/acetone (1:1), stained with gentian violet, and counted. Colonies with cell numbers of more than 50 cells per colony were counted. All experiments were performed in triplicate wells 3 times each.

\section{Cell viability analysis}

Cells were seeded in each well of a 96-well plate $24 \mathrm{hr}$ prior to treatment. Dimethylthiazolyl-2-5diphenyltetrazolium bromide (MTT) dye solution (Sigma, St. Louis, MO, USA) was added into the 96 -well plate 20 $\mathrm{hr}$ post treatment. The plate was incubated at $37^{\circ} \mathrm{C}$ for 4 $\mathrm{hr}$, and the treatment terminated by adding stop solution (isopropanol with $0.04 \mathrm{~N} \mathrm{HCl}$ ). MTT was cleaved by live cells to a colored formazan product. The supernatant was discarded and $150 \mu \mathrm{L}$ DMSO was added to each well, mixed evenly, and the absorbance (A) was measured at $450 \mathrm{~nm}$ within $10 \mathrm{~min}$ using a DG-5031 ELISA Reader [21].

\section{Cell-based scratch assay}

All cell lines were cultured in a 6-well culture plate for $24 \mathrm{hr}$ up to $90 \%-100 \%$ confluences of the base was filled. Scratched wound lines on the upside of cultured cells were created by $200 \mu \mathrm{L}$ yellow micropipette tip. The scratched cells were washed with PBS after removal of culture media. The migration distance was imaged and measured at different time (cells cultured for $0,24,48 \mathrm{hr}$ ) points using a microscope (Olympus, Tokyo, Japan) by Image J program (NIH, USA) [22].

\section{Transwell tumor cell invasion assay}

Cell invasion was quantified in vitro using Transwell chambers with polycarbonate membrane filters $(8-\mu \mathrm{m}$ pore size) coated with a Matrigel ${ }^{\mathrm{TM}}$ (Sigma, St. Louis, USA). Briefly, 48 hours after transfection, cells were washed twice using DMEM and seeded in triplicate in the inner chamber of the insert containing $200 \mu \mathrm{l}$ of serum-free medium. About $700 \mu \mathrm{l}$ of medium containing $10 \%$ fetal bovine serum was added to the lower chamber. The plates were incubated for $24 \mathrm{hr}$ at $37^{\circ} \mathrm{C}$. Then, the non-invading cells from the interior of the inserts were gently removed using a cotton-tipped swab. The cells that had invaded into the bottom surface of the filter were fixed with methanol and stained with hematoxylin. The invasive ability was determined by counting the penetrating cells under a microscope at $\times 400$ magnification on 5 random fields in each well [23].

\section{Apoptosis assay}

The percentage of apoptotic cells was ascertained by dual staining of cells with Annexin $\mathrm{V}$ and propidium iodide [24]. All kinds of cells $\left(2.5 \times 10^{5} / \mathrm{ml}\right)$ were incubated with or without AG-4 $(5.4 \mu \mathrm{M}, 48 \mathrm{~h})$ in presence or absence of various inhibitors at $37^{\circ} \mathrm{C}, 5 \% \mathrm{CO} 2$. Cells were then washed twice in PBS and resuspended in Annexin V binding buffer (10 mM HEPES, $140 \mathrm{mM} \mathrm{NaCl}, 2.5$ $\mathrm{mM} \mathrm{CaCl2}$; pH 7.4). Annexin V-FITC was then added according to the manufacturer's instructions and incubated for 15 minutes under dark conditions at $25^{\circ} \mathrm{C}$. Propium iodide $(0.1 \mu \mathrm{g} / \mathrm{ml})$ was added just prior to acquisition. Data was acquired using a FACS Aria flow cytometer (Becton Dickinson) at an excitation wavelength of $488 \mathrm{~nm}$ and an emission wavelength of $530 \mathrm{~nm}$ and analyzed with BD FACS Diva software (Becton Dickinson).

\section{Cell cycle distribution analysis}

For the determination of cell cycle phase distribution of nuclear DNA, all five kinds of cells $\left(1 \times 10^{6}\right.$ cells $)$ were harvested. Then, cells were fixed with 3\% p-formaldehyde, permeabilized with $0.5 \%$ Triton X-100, and nuclear DNA was labeled with propidium iodide $(125 \mu \mathrm{g} / \mathrm{mL})$ after RNase treatment using Cycle Test Plus DNA reagent 
kit. Cell cycle phase distribution of nuclear DNA was determined on FACS Calibur using Cell Quest Software (Becton-Dickinson). Histogram display of DNA content (x-axis, fluorescence) versus counts (y-axis) has been displayed. Cell Quest statistics was employed to quantitate the data at different phases of the cell cycle.

\section{In vivo tumorigenicity}

All five kinds of cells $\left(1 \times 10^{6}\right.$ cells in $0.1 \mathrm{~mL}$ phosphatebuffered saline) were injected subcutaneously into the dorsal flank of 3-week-old male nude mice, separately. Tumor diameter was measured every 2 or 3 days until 4 weeks. Tumor size $(\mathrm{mm})$ was estimated by measuring the longest diameter of the tumor. Care of animals and all experimental procedures were approved by the Animal Ethics Committee of Tianjin Medical University Cancer Hospital.

\section{Statistical analysis}

The results are expressed as mean $\pm \mathrm{SD}$. The MannWhitney U test was performed to compare the difference of RNF180 mRNA expression among various cell lines. The difference in tumor growth rate between the two groups of nude mice was determined by repeatedmeasures analysis of variance. Significance was defined as $\mathrm{P}<0.05$. All statistical analyses were performed with SPSS 18.0 software.

\section{Ethics}

This study was approved by the Tianjin Medical University Cancer Hospital institutional review board.

\section{FUNDING}

This study was supported in part by grants from the Program of National Natural Science Foundation of China (NO. 81572372), the Application Foundation and Advanced Technology Program of Tianjin Municipal Science and Technology Commission (NO. 15JCYBJC24800), and the Key Program of Tianjin Municipal Science and Technology Commission (NO. 13ZCZCSY20300).

\section{COMPETING INTERESTS}

We have no competing interests.

\section{Authors' contributions}

J.D. and H. L. conceived the study and designed experiments. J. D., Y. H., X. X., C. S., X. G., J. G., and R. Z. performed the experiments. J. D. and H. L. analysed the data. J. D. wrote the manuscript. All authors approved the final version of the manuscript for publication.

\section{REFERENCES}

1. Jones PA, Takai D. The role of DNA methylation in mammalian epigenetics. Science. 2001; 293: 1068-70. doi: 10.1126/science. 1063852 .

2. Esteller M. Epigenetics in cancer. N. Engl. J. Med. 2008; 358: 1148-59. doi: 10.1056/NEJMra072067.

3. Bird A, Taggart M, Frommer M, Miller OJ, Macleod D. A fraction of the mouse genome that is derived from islands of nonmethylated, CpG-rich DNA. Cell. 1985; 40: 91-9. doi: 10.1016/0092-8674(85)90312-5

4. Takai D, Jones PA. Comprehensive analysis of $\mathrm{CpG}$ islands in human chromosomes 21 and 22. Proc. Natl. Acad. Sci. USA. 2002; 99: 3740-5. doi: 10.1073/pnas.052410099.

5. Bird AP. CpG-rich islands and the function of DNA methylation. Nature. 1986; 321: 209-13. doi: 10.1038/321209a0.

6. Pouliot MC, Labrie Y, Diorio C, Durocher F. The Role of Methylation in Breast Cancer Susceptibility and Treatment. Anticancer Res. 2015; 35: 4569-74.

7. Friso S, Udali S, Guarini P, Pellegrini C, Pattini P, Moruzzi S, Girelli D, Pizzolo F, Martinelli N, Corrocher R, Olivieri O, Choi SW. Global DNA hypomethylation in peripheral blood mononuclear cells as a biomarker of cancer risk. Cancer Epidemiol. Biomarkers Prev. 2013; 22: 348-55. doi: 10.1158/1055-9965.EPI-12-0859.

8. Ehrlich M. Cancer-linked DNA, hypomethylation and its relationship to hypermethylation. Curr. Top Microbiol. Immunol. 2006; 310: 251-74. doi: 10.1007/3-540-31181-5 12.

9. Christensen BC, Kelsey KT, Zheng S, Houseman EA, Marsit CJ, Wrensch MR, Wiemels JL, Nelson HH, Karagas MR, Kushi LH, Kwan ML, Wiencke JK. Breast cancer DNA methylation profiles are associated with tumor size and alcohol and folate intake. PLoS Genet. 2010; 6, e1001043. doi: 10.1371/journal.pgen.1001043.

10. Christensen BC, Marsit CJ, Houseman EA, Godleski JJ, Longacker JL, Zheng S, Yeh RF, Wrensch MR, Wiemels JL, Karagas MR, Bueno R, Sugarbaker DJ, Nelson HH, et al. Differentiation of lung adenocarcinoma, pleural mesothelioma, and nonmalignant pulmonary tissues using DNA methylation profiles. Cancer Res. 2009; 69, 6315-21. doi: 10.1158/0008-5472.CAN-09-1073.

11. Christensen BC, Smith AA, Zheng S, Koestler DC, Houseman EA, Marsit CJ, Wiemels JL, Nelson HH, Karagas MR, Wrensch MR, Kelsey KT, Wiencke JK. DNA methylation, isocitrate dehydrogenase mutation, and survival in glioma. J. Natl. Cancer Inst. 2010; 103: 143-53. doi: 10.1093/jnci/djq497.

12. Toyota M, Ahuja N, Ohe-Toyota M, Herman JG, Baylin $\mathrm{SB}$, Issa JP. CpG island methylator phenotype in colorectal cancer. Proc. Natl. Acad. Sci. USA. 1999; 96: 8681-6. doi: 10.1073 / pnas.96.15.8681.

13. Suzuki H, Yamamoto E, Maruyama R, Niinuma T, Kai $\mathrm{M}$. Biological significance of the $\mathrm{CpG}$ island methylator 
phenotype. Biochem. Biophys. Res. Commun. 2014; 455: 35-42. doi: 10.1016/ j.bbrc.2014.07.007.

14. Deng J, Liang $H$, Ying $G$, Zhang R, Wang B, Yu J, Fan D, Hao X. Methylation of CpG Sites in RNF180 DNA Promoter Prediction Poor Survival of Gastric Cancer. Oncotarget. 2014; 5: 3173-83. doi: 10.18632/ oncotarget.1888.

15. Hoeller D, Dikic I. Targeting the ubiquitin system in cancer therapy. Nature. 2009; 458: 438-44. doi: 10.1038/ nature07960.

16. Hershko A. The ubiquitin system for protein degradation and some of its roles in the control of the cell division cycle. Cell Death Differ. 2005; 12: 1191-7. doi: 10.1038/ sj.cdd. 4401702 .

17. Ogawa M, Mizugishi K, Ishiguro A, Koyabu Y, Imai Y, Takahashi R, Mikoshiba K, Aruga J. Rines/RNF180, a novel RING finger gene-encoded product, is a membranebound ubiquitin ligase. Genes Cells 2008; 13: 397-409. doi: 10.1111/j.1365-2443.2008.01169.x.

18. Balastik M, Ferraguti F, Pires-da Silva A, Lee TH, AlvarezBolado G, Lu KP, Gruss P. Deficiency in ubiquitin ligase TRIM2 causes accumulation of neurofilament light chain and neurodegeneration. Proc. Natl. Acad. Sci. USA. 2008; 105: 12016-21. doi: 10.1073/pnas.0802261105.

19. Cheung KF, Lam CN, Wu K, Ng EK, Chong WW, Cheng AS, To KF, Fan D, Sung JJ, Yu J. Characterization of the gene structure, functional significance, and clinical application of RNF180, a novel gene in gastric cancer. Cancer. 2012; 118: 947-59. doi: 10.1002/cncr.26189.

20. Xie X, Deng J, Hou Y, Cui J, Wu W, Ying G, Dong Q, Hao $\mathrm{X}$, Liang H. Evaluating the clinical feasibility: The direct bisulfite genomic sequencing for examination of methylated status of E3 ubiquitin ligase RNF180 DNA promoter to predict the survival of gastric cancer. Cancer Biomark. 2015; 15: 259-65. doi: 10.3233/CBM-150466.

21. Germack R, Dickenson JM. Adenosine triggers preconditioning through MEK/ERK1/2 signalling pathway during hypoxia/reoxygenation in neonatal rat cardiomyocytes. J. Mol. Cell Cardiol. 2004; 37: 989-99. doi: 10.1016/j.yjmcc.2005.06.001.

22. Sung HJ, Kim Y, Kang H, Sull JW, Kim YS, Jang SW, Ko J. Inhibitory effect of Trolox on the migration and invasion of human lung and cervical cancer cells. Int. J. Mol. Med. 2012; 29: 245-51. doi: 10.3892/ijmm.2011.832.

23. Zhou B, Chen H, Wei D, Kuang Y, Zhao X, Li G, Xie J, Chen P. A novel miR-219-SMC4-JAK2/Stat3 regulatory pathway in human hepatocellular carcinoma. J. Exp. Clin. Cancer Res. 2014; 33: 55. doi: 10.1186/1756-9966-33-55.

24. Das B, Chowdhury C, Kumar D, Sen R, Roy R, Das P, Chatterjee M. Synthesis, cytotoxicity, and structure-activity relationship (SAR) studies of andrographolide analogues as anti-cancer agent. Bioorg. Med. Chem. Lett. 2010; 20: 6947-50. doi: 10.1016/j.bmcl.2010.09.126. 